\title{
The diagnosis and differential diagnosis of endogenous Cushing's syndrome
}

\author{
Polyzois Makras, ${ }^{1}$ Georgios Toloumis, ${ }^{1}$ Dimitrios Papadogias, ${ }^{2}$ Gregory A. Kaltsas, ${ }^{3,4}$ \\ Michael Besser ${ }^{4}$
}

${ }^{1}$ Department of Endocrinology \& Diabetes, 251 Hellenic Air Force General Hospital, Athens, Greece, ${ }^{2}$ Department of Endocrinology \& Diabetes, "IASO" General Hospital, Athens, Greece, ${ }^{3}$ Department of Pathophysiology, National University of Athens, Athens, Greece, ${ }^{4}$ Department of Endocrinology, St Bartholomew's Hospital, London, United Kingdom

\begin{abstract}
Cushing's syndrome (CS) is a physically and psychologically disabling disease associated with high morbidity resulting from inappropriate elevation of circulating free cortisol levels. The main features of CS are disturbance of the normal circadian rhythm of cortisol secretion, impairment of the normal feedback of the hypothalamo-pituitary-adrenal (HPA)-axis, and excessive integrated 24 hours cortisol secretion. All biochemical tests used for the diagnosis of CS rely upon the ascertainment of a disturbance of these features. However, the diagnosis of CS (endogenous hypercortisolism) still remains a challenge, although the evolution of several diagnostic tests has allowed diagnosis at an earlier stage. In the initial investigation of CS, tests of high sensitivity are required to identify patients at risk, which are followed by tests of high specificity to confirm the diagnosis and establish the precise aetiology. This review will discuss the various causes of endogenous CS and focus on established and evolving diagnostic procedures used for its diagnosis, as several studies with large number of patients have recently appeared in the literature validating current practice and proposing improved diagnostic algorithms.
\end{abstract}

Key words: Cushing's disease, Cushing's syndrome, Pseudo-Cushing's, Subclinical Cushing's

\section{INTRODUCTION}

Endogenous Cushing's syndrome (CS) is a clinical state resulting from prolonged, inappropriate

\footnotetext{
Address for correspondence:

Dr. Gregory Kaltsas MD FRCP, Dept. of Pathophysiology, Athens University School of Medicine, Laiko General Hospital, Mikras Asias 75, 115 67, Tel: 00302107456 657, Fax: 00302107462 664, E-mail address: gkaltsas@endo.gr Received 19-07-06, Revised 25-08-06, Accepted 30-08-06
}

exposure to excessive cortisol secretion with subsequent loss of the normal feedback mechanism of the hypothalamo-pituitary-adrenal (HPA) axis and the normal circadian rhythm of cortisol secretion. ${ }^{1} \mathrm{Al}-$ though CS secondary to exogenous cortisol administration is far more common and easily identifiable from the history, endogenous CS is relatively rare and its diagnosis, differential diagnosis, and management is continuously evolving. ${ }^{2-4}$ The majority of 
cases of endogenous CS are related to excessive adrenocorticotrophin (ACTH) production, most commonly from a pituitary adenoma, or from a non-pituitary tumour (ACTH-dependent CS). ${ }^{3,5}$ Less often endogenous CS is secondary to hyperfunctioning adrenocortical tumours, bilateral adrenal hyperplasia, and/or dysplasia (ACTH-independent CS). ${ }^{3,4,6,7}$ Endogenous CS needs to be distinguished from the so-called 'pseudo-Cushing's' states, that are associated with biochemical evidence of excessive cortisol secretion without the clinical manifestations of the syndrome. ${ }^{1}$

During recent years the possibility of CS is being suspected at an earlier stage in its natural course and states of 'subclinical CS' are increasingly being recognized, thus calling for the incorporation of new diagnostic approaches to established diagnostic algorithms. ${ }^{1,8}$ Making the diagnosis and establishing the exact aetiology of CS is of fundamental importance, as sustained cortisol hypersecretion is associated with considerable morbidity and mortality, necessitating definitive treatment of the underlying cause of the hypercortisolism. ${ }^{1}$ Similarly, states of subclinical CS can also be associated with specific metabolic alterations and subsequent morbidity. ${ }^{9}$

\section{EPIDEMIOLOGY AND AETIOLOGY OF CS}

Cushing's syndrome is a relatively rare disorder with an estimated incidence of 5-6 cases per $10^{6} \mathrm{popu}-$ lation..$^{10}$ In the majority of series with a large number of patients with clinically apparent CS, approximately $80 \%$ of cases are ACTH-dependent (secondary to a tumour hypersecreting ACTH), whereas $20 \%$ are ACTH-independent (Table 1). ${ }^{1,3,5}$ However, there are widely varying estimates regarding the exact incidence of particular causes of CS, as some studies have suggested a much higher incidence of adrenal adenoma surpassing that of ACTH secreting tumours; this has also been confirmed in more recent series when cases of subclinical CS mainly of adrenal origin are included, reaching an overall incidence of 7.5 per $10^{5}$ population. ${ }^{8}$

An ACTH-secreting pituitary adenoma is present in approximately $80 \%$ of cases of ACTH-dependent CS and this entity is referred to as Cushing's disease (CD); ACTH-secreting carcinomas are very
Table 1. Etiology of Cushing's syndrome

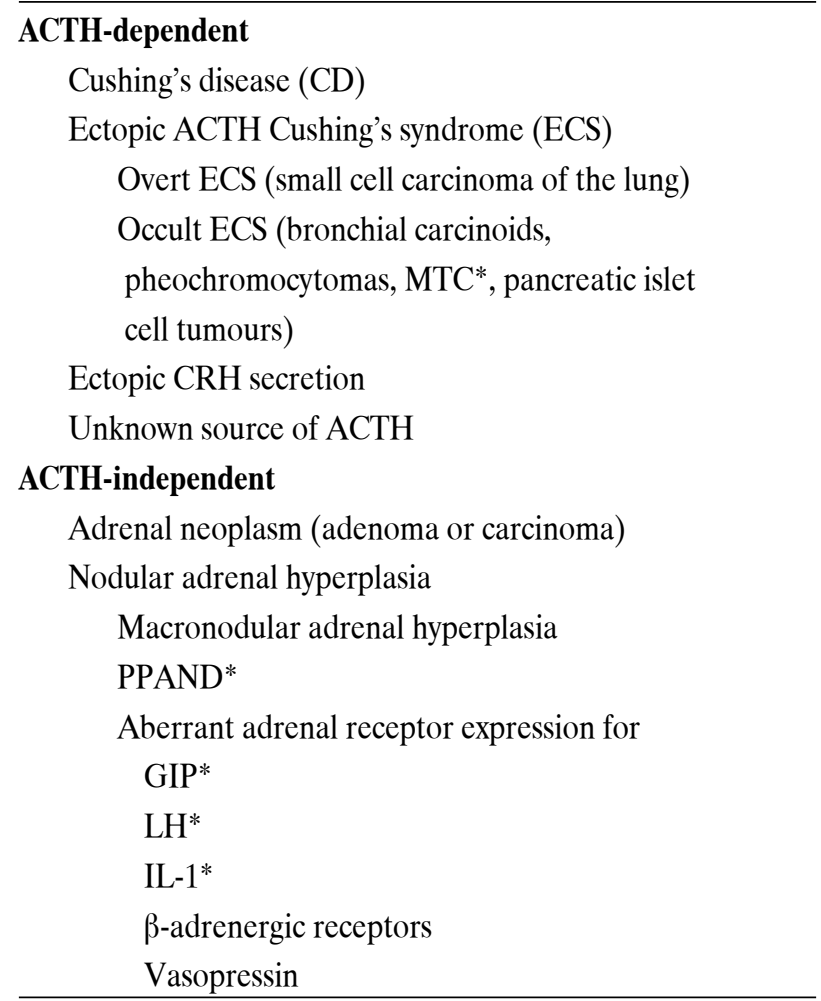

Adapted from: Stewart PM ${ }^{136}$

*MTC: Medullary Thyroid carcinoma; PPAND: Primary pigmented adrenal nodular dysplasia; GIP: gastric inhibitory peptide; LH: Luteinizing Hormone; IL-1: Interleukin - 1

rare with approximately 20 cases described up to date. ${ }^{11,12}$ The remaining causes of ACTH-dependent $\mathrm{CS}$ are secondary to non-pituitary tumours secreting ACTH, the so-called ectopic ACTH syndrome in which ACTH is secreted from a non-pituitary tumour (ectopic CS, ECS). ${ }^{1,13}$ This syndrome was originally described in patients with small cell lung carcinomas, but it soon became apparent that patients harbouring these, rapidly growing, tumours usually do not develop all the classical features of CS and exhibit a distinct phenotype. ${ }^{14}$ During recent years the occult ectopic ACTH syndrome (oECS), mostly from bronchial carcinoids, has been recognized with increasing frequency and currently represents a major diagnostic challenge, as its clinical and biochemical features closely resemble those of CD. ${ }^{1,3,5}$ Adrenal tumours (usually adenoma and carcinoma) are the most common adrenal lesions associated with CS; as cortisol is secreted autonomously, it suppresses pituitary $\mathrm{ACTH}$ and these lesions give rise to ACTH-in- 
dependent CS. ${ }^{15}$ Adrenal adenomas are of relatively small size and represent the most common causes of ACTH-independent CS. ${ }^{1}$ Adrenal carcinomas are usually larger than adenomas, exhibit capsular or vascular invasion infiltrating surrounding tissues, and may develop distant metastases mainly in the liver. Distinguishing between adrenal adenomas and carcinomas may occasionally be difficult in the absence of metastases. ${ }^{16-18}$ In general, adrenal tumours greater than $6 \mathrm{~cm}$ in diameter (approximately $100 \mathrm{~g}$ in weight), secreting more than one class of steroids, typically androgens, in addition to cortisol, should be regarded as potentially malignant. ${ }^{16}$ In approximately $1-2 \%$ of ACTH-independent CS a pathology other than an adrenal tumour can be found (Table 1). The aetiology, clinical, biochemical, radiological, and pathological features of these rare forms of CS will be discussed later in detail.

Each of the principal causes of CS is associated with characteristic responses to dynamic suppressive and stimulating testing of the HPA-axis which mainly include assessment of feedback regulation of cortisol secretion following the administration of dexamethasone and cortisol response to corticotrophin releasing hormone (CRH) administration., ${ }^{3,19}$ In contrast to classical CS, subclinical CS, resulting from dysregulated cortisol secretion but not always associated with a clinically recognizable syndrome, is increasingly being identified..$^{20}$ This form of CS may be associated, at least to some extent, with some of the long-term complications of full-blown CS such as the metabolic syndrome, arterial hypertension, obesity, and/or diabetes mellitus. ${ }^{9}$ Earlier series have shown a 50\% 5-year mortality in untreated or partially treated cases of severe CS; ${ }^{1,3,5}$ however, with earlier diagnosis and modern treatment the outlook has improved greatly. ${ }^{1}$ The impact that subclinical forms of CS may exert on morbidity and probably mortality of these patients needs to be assessed by a prospective study.

\section{DIAGNOSTIC OVERVIEW}

The clinical symptoms/signs of CS provide the stimulus for further biochemical and radiological evaluation..$^{1}$ The biochemical diagnosis of CS involves confirmation of hypercortisolism and must be estab- lished before any attempt at differential diagnosis, since the reported sensitivity, specificity, and diagnostic accuracy of all tests currently used are valid only during periods of sustained hypercortisolism. ${ }^{3}$ Cases with a clinical suspicion of CS and negative initial screening tests should be re-evaluated at a later stage (usually 4-6 monthly) and all invasive procedures should be postponed until hypercortisolism is documented. ${ }^{1}$

\section{CLINICAL FEATURES OF OVERT AND SUBCLINICAL CS}

Cushing's syndrome is a multisystem disorder in which excessive glucocorticoid levels cause alterations in virtually every part of the body, presumably in direct proportion to the length of time of exposure to and magnitude of the hypercortisolism. ${ }^{1,4}$ The commonest clinical symptoms and signs of CS in several series with a large number of patients and the effects of hypercortisolism on tissues and metabolism are shown in Tables 2 and 3, respectively. ${ }^{1}$ The most common presenting complaints are often nonspecific, such as weight-gain, fatigue, lethargy, and depression, whereas the signs of CS may vary in time and differ in severity. ${ }^{1}$ Associated problems, such as diabetes mellitus, hypertension or osteoporosis, may also bring the patient to medical attention. ${ }^{4}$

Patients with severe hypercortisolism will show

Table 2. Prevalence of signs and symptoms in Cushing's syndrome.

\begin{tabular}{lrll}
\hline Signs & \multicolumn{3}{l}{ Symptoms } \\
\hline Obesity & $97 \%$ & Weight gain & $91 \%$ \\
$\quad$ Truncal & $46 \%$ & Menstrual disturbances & $84 \%$ \\
$\quad$ Generalised & $55 \%$ & Hirsutism & $81 \%$ \\
Plethora & $94 \%$ & Psychiatric disturbances & $62 \%$ \\
Moon face & $88 \%$ & Backache & $43 \%$ \\
Hypertension & $74 \%$ & Muscle wasting & $29 \%$ \\
Bruising & $62 \%$ & Fractures & $19 \%$ \\
Red-purple striae & $56 \%$ & Scalp hair loss & $13 \%$ \\
Muscle weakness & $56 \%$ & & \\
Ankle edema & $50 \%$ & & \\
Pigmentation & $4 \%$ & & \\
\hline
\end{tabular}

Data from: Ross EJ, Linch $\mathrm{DC}^{137}$ 
Table 3. Diverse effects of hypercortisolism upon tissues and metabolic functions and commonest clinical findings.

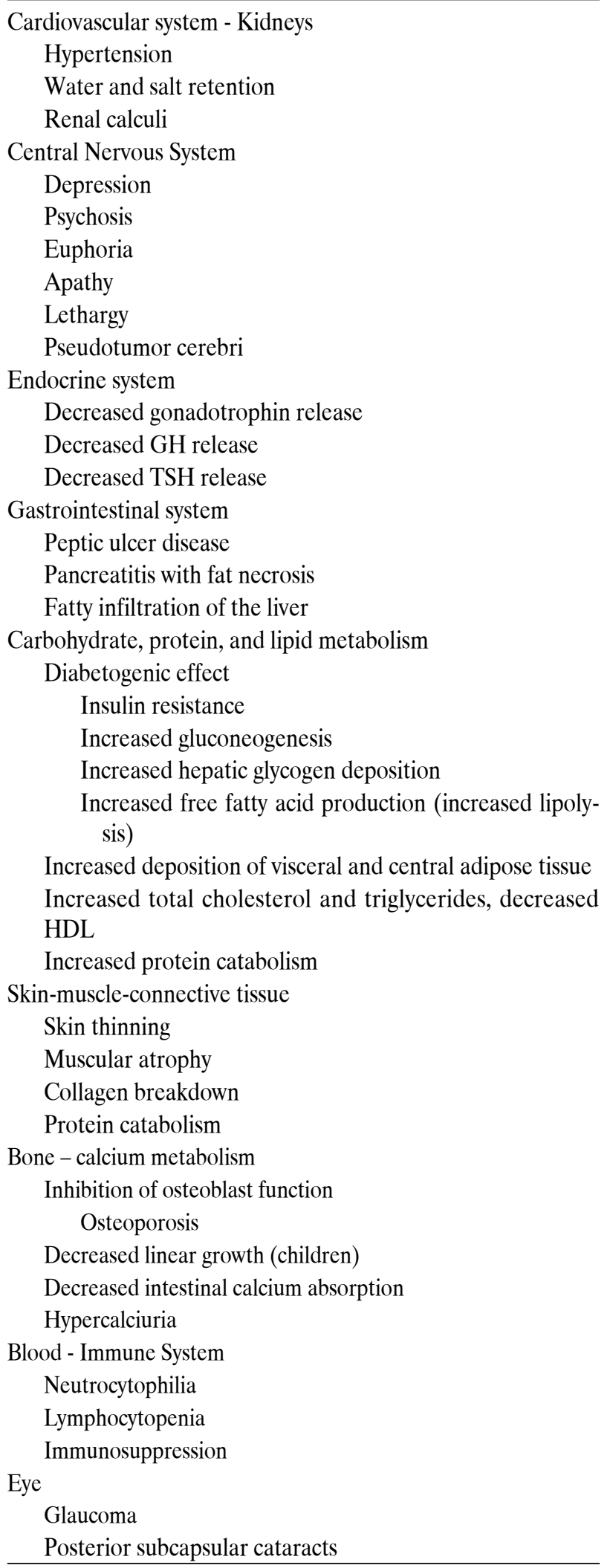

Adapted from:Stewart PM ${ }^{136}$ \& Yanovski JA, Cutler GB ${ }^{138}$ the characteristic Cushingoid appearance except in some patients with the ectopic ACTH syndrome, whereas patients with only subtle hypersecretion of cortisol may exhibit less obvious physical changes. In addition, some features found in patients with CS such as obesity, hypertension, mood changes, and menstrual irregularities are also common in the general population. In such cases the presence of specific signs, such as proximal myopathy, ecchymoses and thinning of the skin, should orientate towards CS rather than the presence of a pseudo-cushingoid state. ${ }^{1,21,22}$ Alcoholism can result in clinical and biochemical appearances identical to CS; however, the history is suggestive and the clinical and biochemical abnormalities disappear within days if the patient stops drinking. In children, weight-gain associated with growth retardation is a prominent feature implying the presence of CS. ${ }^{1,20,23-26}$ When considering the diagnosis of CS, another strategy which may often be helpful is to examine serial photographs for evidence of progressively appearing characteristic physical changes. ${ }^{1,27}$ For unknown reasons any cause of CS can exhibit cyclical and intermittent secretion, which can extend over long periods of time, complicating the diagnostic process further. ${ }^{1,28,29}$ In such cases, confirmation of hypercortisolism is needed to allow reliable interpretation of the diagnostic tests; if hypercortisolism is absent at presentation but the diagnosis remains strongly suspected, re-evaluation at a later stage may be required. ${ }^{30}$

\section{BIOCHEMICAL DIAGNOSIS AND DIFFERENTIAL DIAGNOSIS}

The investigation of suspected CS is a two-step process involving the confirmation of the hypercortisolism and then the identification of its precise cause. The main biochemical features characteristic of CS are excessive endogenous integrated cortisol secretion, loss of the normal feedback of the HPA-axis, and abnormal circadian rhythm of cortisol secretion. ${ }^{1}$ All biochemical tests used in the diagnosis of CS rely upon these parameters and require the presence of hypercortisolism. ${ }^{20}$ In addition, a detailed assessment of the presence of other illnesses, drugs, alcohol intake or neuropsychiatric conditions should be undertaken, since their presence may be a confounding factor affecting biochemical evaluation. ${ }^{1}$ Biochemical 
indices such as serum potassium $(\mathrm{K})$ and bicarbonate $\left(\mathrm{HCO}_{3}\right)$ concentrations have also been used as means for the diagnosis and to distinguish between the different causes of ACTH-dependent CS. ${ }^{27}$ Low serum K levels are found in approximately $10 \%$ of patients with CD and approximately $90 \%$ of patients with the ECS. ${ }^{52}$ Serum K levels have been shown to relate to the degree of hypercortisolism following the delineation of the role of $11 \beta$ hydroxydehydrogenase (11 $\beta$ HSD) on cortisol metabolism. ${ }^{27}$ Measurement of serum K should always be performed in such patients as well as serum $\mathrm{HCO} 3$, as the latter is not affected by haemolysis and is always elevated in states of chronic $\mathrm{K}$ deficiency.

\section{Cortisol Circadian Rhythm}

Normally serum cortisol begins to rise at 0300 0400 hours reaching a peak at 0700-0900 hours, with levels then falling for the remainder of the day. ${ }^{31}$ Patients with CS show either complete abolition of this 'normal' circadian rhythm or the presence of a rhythm which is set at higher levels..$^{32,33}$ Early morning cortisol measurement shows considerable overlap between patients with CS and normal subjects; however, this is reduced to $17 \%$ when cortisol measurement is performed between 1600-2100 hours and to $3.4 \%$ when cortisol measurement is performed at 2300 hours. ${ }^{34}$ After excluding any confounding factors such as drugs and pseudo-Cushing's states, ${ }^{35,36}$ a single sleeping (midnight) cortisol was found to be greater than $50 \mathrm{nmol} / \mathrm{L}(1.8 \mu \mathrm{g} / \mathrm{dl})$ in each one of 150 patients with CS, and substantially less in all controls, thus achieving a sensitivity of $100 \%$. Thus, this test appears to be the most valid and efficient way of confirming or excluding CS. ${ }^{37}$ Similar results have been obtained in another series evaluating the value of midnight salivary cortisol in distinguishing CS from pseudo-Cushing's states: ${ }^{38}$ however, this test requires inpatient admission for at least 48 hours. ${ }^{1,38}$ In another pertinent study it was shown that use of salivary midnight cortisol had similar sensitivity and specificity to serum cortisol. Saliva cortisol determination has the advantage that it can be performed more easily, but it remains to be confirmed and validated as a diagnostic tool of $\mathrm{CS}^{39}$ One major problem of this method is that the patients cannot produce a salivary specimen while asleep.

\section{Urinary free cortisol (UFC)}

Under normal conditions, approximately $10 \%$ of serum cortisol is unbound and physiologically active; although the majority is reabsorbed in the renal tubules, a small percentage, approximately $1 \%$, is excreted unaltered in the urine. ${ }^{1}$ Excessive cortisol secretion saturates circulating cortisol binding globulin $(\mathrm{CBG})$ resulting in an increase in UFC. ${ }^{20}$ Collection of 24 hours urine for estimation of UFC levels is used as a screening test for the diagnosis of CS and has surpassed the previously used cortisol metabolite measurements; both radioimmunoassay (RIA) and high performance liquid chromatography (HPLC) methods have been utilized for this purpose. ${ }^{1}$ Initial studies showed a false negative and a false positive rate of $5.6 \%$ and $3.3 \%$, respectively, ${ }^{34}$ whereas more recent studies showed a diagnostic sensitivity and specificity in differentiating patients with CS from normal subjects and obese individuals of $100 \%$ and $98 \%$, respectively. ${ }^{40}$ However, in patients with mild CS, UFC levels may be consistently normal, ${ }^{41}$ whereas elevated UFC levels may also be found in pregnant women, 40-60\% of depressed inpatients, patients with Polycystic Ovarian Syndrome (PCOS), and in "pseudo-Cushing's" states, thus reducing its specificity. ${ }^{1,42-44}$ Therefore, although UFC estimations exhibit relatively high sensitivity, they are associated with a relatively low specificity. ${ }^{27}$ When several UFC collections are normal, CS is unlikely except in the case of cyclical CS. ${ }^{1}$ In such cases an early morning $\mathrm{UFC} / \mathrm{creatinine}(\mathrm{nmol} / \mathrm{l}: \mathrm{mmol} / \mathrm{l})$ ratio of greater than 50 may be suggestive of $\mathrm{CS} .{ }^{30}$ Conversely, when UFC values are four-fold greater than the upper limit of normal, this can be considered as diagnostic of CS. ${ }^{1}$ HPLC represents the method of choice for measuring UFC levels as it allows the separation of various urinary glucocorticoids and metabolites whereas RIA can be influenced by some cortisol metabolites and several synthetic glucocorticoids. ${ }^{1}$ Falsely raised UFC levels can occasionally occur when using HPLC by interfering substances, such as digoxin and carbamazepine, which co-elute with cortisol. ${ }^{23,24}$

\section{Dexamethasone Suppression Test (DST)}

The purpose of the DST is to demonstrate the impaired feedback regulation of the HPA-axis in any form of CS. Administration of dexamethasone, 
which is not measured in the routine cortisol assays, results in suppression of the HPA-axis in normal individuals and a fall in plasma and urinary cortisol; measurement of serum cortisol is easier and of greater diagnostic accuracy. ${ }^{1}$ Several variations of the DST have been described. ${ }^{1}$ The overnight DST involves the oral administration of $0.5-2 \mathrm{mg}$ of dexamethasone (most commonly $1 \mathrm{mg}$ ) at 2300 hours and measurement of plasma cortisol at 0800 or 0900 hours the next morning; there appears to be no better discrimination using $2 \mathrm{mg}$ rather than $1 \mathrm{mg}$ of dexamethasone. ${ }^{34}$ Because of its ease of administration to an outpatient, the $1 \mathrm{mg}$ DST has been advocated by many as the screening test of choice for the demonstration of endogenous hypercortisolism. ${ }^{1}$ Some patients with CS may be extremely sensitive to dexamethasone suppressibility exhibiting false negative results. ${ }^{45}$ However, accepting lower values of cortisol suppression can increase the false positive results, thus decreasing the specificity of the test. ${ }^{27}$

With adequate, written instructions for administration of $0.5 \mathrm{mg}$ of dexamethasone every 6 hours, the standard 48 hours low dose DST (LDDST) can be performed reliably on an outpatient basis. In this setting we can obtain a high diagnostic accuracy with a sensitivity of $98 \%$ using a post-dexamethasone serum cortisol value of less than $50 \mathrm{nmol} / \mathrm{l}(1.8 \mu \mathrm{g} / \mathrm{l})$ as indicating adequate suppression. ${ }^{4,27,37,41}$ In accordance with this, a recent review assessing the utility of the DST in the diagnosis of $\mathrm{CS}^{46}$ as well as a recent consensus statement ${ }^{4}$ suggested that a plasma cortisol greater than $50 \mathrm{nmol} / 1(1.8 \mu \mathrm{g} / \mathrm{dl})$ after overnight $1 \mathrm{mg}$ dexamethasone administration merit further evaluation.

By acceptance of such quoted cortisol levels as indicative of adequate suppression, false positive rates may be higher, albeit with a specificity of $87.5 \%$ and $97-100 \%$ for the $1 \mathrm{mg}$ overnight DST and the LDDST, respectively. ${ }^{47,48}$ False positive results can occur because of failure to take dexamethasone as prescribed, decreased dexamethasone absorption or accelerated hepatic metabolism (usually as a consequence of taking hepatic enzyme inducers as phenytoin, carbamazepine, barbiturates, aminoglutethimide or rifampicin), and/or increased concentration of cortisol binding globulin (CBG) (pregnancy or estrogen treatment). In moderate or severe primary depression, resistance to DST may also cause diagnostic confusion, as agitated depression is a common finding of CS. ${ }^{49,50}$ In primary depression, adequate cortisol suppression to dexamethasone administration is restored following successful treatment of the depression; similarly, alcoholic patients demonstrate normal cortisol suppression to DST after alcohol is withheld for some days. ${ }^{41}$ Although some investigators have advocated the intravenous infusion of dexamethasone as a means of overcoming problems with compliance and/or accelerated metabolism, these tests are not used routinely. ${ }^{1}$

\section{Cyclical CS}

Sometimes it is not possible to make the diagnosis of CS with confidence despite high clinical and occasionally biochemical suspicion, because patients may exhibit cyclical or intermittent cortisol secretion. ${ }^{28,29}$ In such cases, inpatient admission with sampling for midnight sleeping cortisol or measurement of early morning UFC/creatinine ratio may be required..$^{30,37,51}$ As such patients usually have mild disease, they can be left untreated and reinvestigated at regular intervals (4-6 months).

\section{DIFFERENTIAL DIAGNOSIS OF CUSHING'S SYNDROME AND PSEUDO-CUSHING'S STATES}

Following the diagnosis of CS, the next step is to establish the cause by measuring plasma ACTH levels. A plasma ACTH of less than $10 \mathrm{pg} / \mathrm{ml}$ at 0900 hours, with concomitant increased cortisol production, is suggestive of ACTH-independent CS. Patients with ACTH-dependent CS usually have ACTH levels greater than $10 \mathrm{pg} / \mathrm{ml} .{ }^{1}$ Imaging of the adrenal glands without further biochemical testing is suggested when ACTH level of less than $5 \mathrm{pg} / \mathrm{ml}$ at $0900 \mathrm{~h}$ is found..$^{15} \mathrm{~A}$ few patients with pituitary-dependent CS may occasionally have undetectable, i.e less than $10 \mathrm{pg} / \mathrm{ml}$, plasma ACTH levels. ${ }^{19,52,53}$ In such cases several ACTH measurements and/or measurement of ACTH following $\mathrm{CRH}$ administration may be required as patients with $\mathrm{ACTH}$-dependent CS exhibit an $\mathrm{ACTH}$ response to $\mathrm{CRH}$ exceeding $20 \mathrm{pg} / \mathrm{ml}^{15}$

\section{Differential diagnosis of ACTH-dependent CS}

Although approximately $80 \%$ of patients with ACTH-dependent CS will be shown to have CD, 
their distinction from patients with the ECS (particularly the oECS) is not straightforward. With the introduction of pituitary microadenoma removal as the treatment of choice in patients with $\mathrm{CD}$, an accurate differential diagnosis is critical. ${ }^{54}$ Plasma ACTH levels tend to be higher in the oECS compared to $\mathrm{CD}$, but there is a large overlap using either RIA or IRMA, and thus these methods offer poor discriminatory ability. ${ }^{19,52,53}$ In addition, although the presence of POMC precursors, due to partial processing to $\mathrm{ACTH}$, is indicative of the ECS (including oECS), it is also found in the majority of pituitary macrodenomas and occasionally in microadenomas, thus limiting its diagnostic accuracy. ${ }^{1}$ As some tumours causing oECS may not be radiologically evident (particularly bronchial carcinoids), and only become apparent many years after the diagnosis of CS, several other tests have been developed.

\section{High dose dexamethasone testing (HDDST)}

This test is based on the fact that the corticotroph tumour cells in $\mathrm{CD}$ retain some responsiveness to the negative feedback effects of glucocorticoids, while tumours ectopically secreting ACTH do not. ${ }^{27}$ The standard HDDST that assesses the degree of cortisol suppressibility to dexamethasone administration ( $2 \mathrm{mg}$ of dexamethasone every $6 \mathrm{~h}$ for $48 \mathrm{~h}$ ) was initially performed on 24 hours urine collections; a $50 \%$ or greater suppression was consistent with $\mathrm{CD}$; however, currently serum cortisol is generally used. ${ }^{1}$ Several modifications of the HDDST have appeared in an attempt to obtain maximal sensitivity and specificity; overall, the sensitivity of the HDDST ranges from $65-100 \%$ and the specificity from $60-100 \%$, even when serum cortisol instead of UFC measurement is used and after using intravenous rather than oral dexamethasone..$^{1,34,52,55-58}$ Our own practice is to perform the HDDST in an identical manner to the LDDST, except that a dose of $2 \mathrm{mg}$ of dexamethasone is administere every 6 hours. ${ }^{1,59} \mathrm{~A}$ fall of over $50 \%$ in the post-dexamethasone serum cortisol compared to the basal value is indicative of $\mathrm{CD}$ with a sensitivity varying from 60 to $80 \%$ and a high specificity which can be improved further if a cut-off of cortisol suppression of greater than $80 \%$ is used; ${ }^{4,23}$ false positive and/or positive results occur in approximately $10 \%$ of the cases. ${ }^{41}$ Unfortunately, no stringent criteria exist for the differential diagnosis between $\mathrm{CD}$ and ectopic
ACTH production ${ }^{1}$ and, although the HDDST can detect patients with $C D$ with relatively high sensitivity, it does not accurately exclude those with ectopic ACTH production. ${ }^{15}$ Lately, the effectiveness of the HDDST has been questioned as on several occasions the sensitivity and the specificity of the test appears to be less accurate than the pre-test statistical likelihood of CD. ${ }^{60,61}$ A recent, single institution study comparing directly the performance of the LDDST and HDDST using serum cortisol measurements revealed that most of the diagnostic information provided by the HDDST could be predicted from the LDDST; if cortisol was suppressed by more than $30 \%$, this invariably predicted 'adequate' suppression $(>50 \%)$ to the HDDST. ${ }^{24}$ Due to these inherent limitations of the test, some authors have suggested the abandonment of the HDDST as it provides little diagnostic advantage in the differential diagnosis of ACTH-dependent CS in relation to other tests both in adult ${ }^{24}$ and paediatric patients. ${ }^{62}$

\section{Metyrapone testing}

Metyrapone blocks cortisol synthesis by preventing the hydroxylation of $11 \beta$-deoxycortisol, and therefore induces a rise in $\mathrm{ACTH}$ and subsequent rise in urinary 17-OHCS and/or serum 11-deoxycortisol in patients with CD but not ECS; this has been associated with a $71 \%$ sensitivity and $100 \%$ specificity, respectively. ${ }^{63}$ However, as patients with ACTHindependent CS may occasionally exhibit such a response, this test is no longer used routinely. ${ }^{41}$

\section{Corticotrophin releasing hormone (CRH), vasopressin (AVP), desmopressin stimulation tests}

Pituitary ACTH secretion is regulated principally by CRH and AVP; AVP sensitizes the corticotroph to CRH and also exerts some intrinsic ACTH-releasing activity. ${ }^{31}$ Normal pituitary and ACTH-secreting pituitary tumours express $\mathrm{CRH}$ receptors and exhibit an exaggerated ACTH response to both ovine and human CRH. ${ }^{15,27,49}$ In contrast, non-pituitary tumours usually do not express such receptors and exhibit a blunted ACTH response following stimulation with these agents. ${ }^{15,41}$ Although the $\mathrm{CRH}$ test is of no value in establishing the diagnosis of $\mathrm{CS}$, it is an important diagnostic tool in discriminating between pituitary and ectopic ACTH secretion. ${ }^{31,37}$ Using 
peak cortisol increments greater than $14 \%$ and $20 \%$ following the i.v. administration of $100 \mu \mathrm{g}$ of $\mathrm{CRH}$, sensitivity and specificity ranging from $70 \%$ to $93 \%$ and $95 \%$ to $100 \%$, respectively, have been obtained. ${ }^{15}$ Although most of the patients with CD who do not respond to CRH exhibit suppression to HDDST, ${ }^{55,58}$ there are still cases in which ACTH-secreting nonpituitary tumours may exhibit a response suggestive of CD to both the HDDST and CRH stimulation test. ${ }^{64}$ Lysine or arginine AVP and desmopressin, a long-acting analogue of AVP, stimulate ACTH release via the specific corticotroph AVP receptor, particularly from ACTH secreting pituitary tumours, and have also been used for the differential diagnosis of ACTH-dependent CS; however, these tests appear to be inferior to the $\mathrm{CRH}$ stimulation test. ${ }^{1,65,66}$ Desmopressin (DDAVP) lacks the $\mathrm{V}_{1}$ renal receptor and thus the pressor side effects observed with the AVP analogues. ${ }^{1}$ In order to improve the sensitivity of CRH stimulation, the combination of $10 \mu \mathrm{g}$ of DDAVP i.v. and 100 $\mu \mathrm{g}$ of human CRH iv. was administered to 17 patients with histologically proven $\mathrm{CD}$ and 5 patients with the oECS; patients with CD demonstrated a $39 \%$ or more cortisol rise compared to a $29 \%$ or less cortisol rise of patients with the oECS, achieving a sensitivity and a specificity of $100 \% .{ }^{67}$ However, this series included a relatively small number of patients with oECS and the discrimination remained quantitative in nature. It therefore remains to be seen whether the coadministration of hCRH and DDAVP presents an improvement over the standard CRH stimulation test. ${ }^{1}$ Nevertheless, DDAVP might be useful in the discrimination between $\mathrm{CD}$ and pseudo- $\mathrm{CS}^{29}$ and the postoperative assessment of CD..$^{31,68}$

\section{The combined dexamethasone-CRH (DST-CRH) test}

The DST-CRH test was originally designed to distinguish CS from 'pseudo-cushingoid' states. ${ }^{44}$ Later it was shown that this test can also distinguish patients with endogenous hypercortisolism from normal subjects ${ }^{69}$ and between different subtypes in patients with depression. ${ }^{70}$ Following a formal LDDST and 2 hours after the last dexamethasone administration, $\mathrm{CRH}(1 \mathrm{mcg} / \mathrm{Kg})$ is administered intravenously at $0800 \mathrm{~h}$; a plasma cortisol level greater than $1.4 \mu \mathrm{g} / \mathrm{dL}(38 \mathrm{nmol} / \mathrm{L})$ measured 15 minutes after $\mathrm{CRH}$ administration is reported to correctly identify patients with CS. ${ }^{44,60}$ This test, however, is cumbersome and in addition relatively few cortisol assays have the necessary sensitivity to discriminate such low cortisol values. ${ }^{71}$ Although no established criteria for plasma ACTH response to this test exist, measurement of ACTH may be more relevant as sensitivity for ACTH measurements is better than that of cortisol. ${ }^{71}$ Furthermore, it was recently shown that the addition of CRH to the standard LDDST protocol did not confer any additional diagnostic benefit, while it guided to further unnecessary testing due to false positive results in individuals in which a standard LDDST had previously excluded CS. ${ }^{72}$

\section{Salivary cortisol measurement}

Several studies have documented that failure to decrease serum cortisol at midnight, while the patient is asleep, is associated with a sensitivity approaching $100 \%$ in identifying patients with CS; however, this approach requires hospitalization for 48 hours and is not easily performed..$^{37,73}$ The concentration of cortisol in saliva appears to be an accurate index of free, biologically active circulating cortisol and may be used as an alternative to serum cortisol. ${ }^{38,71}$ As it is difficult to sample saliva cortisol in sleeping patients ${ }^{71}$ measurement of morning saliva cortisol following an 1mg DST may further improve the accuracy of the late night salivary cortisol. ${ }^{60,74} \mathrm{Al}$ though the use of salivary cortisol as the primary screening test for CS is supported by some, further clinical experience with validated commercial assays is needed. ${ }^{1}$

\section{Invasive testing}

None of the non-invasive tests mentioned above seems to achieve the desirable diagnostic accuracy of approximately $100 \%$. Bilateral simultaneous inferior petrosal sinus sampling (BIPSS) with CRH stimulation provides the most accurate and reliable means of distinguishing pituitary from non-pituitary ACTH-dependent CS and currently represents the 'gold standard' in the differential diagnosis of $\mathrm{CS}^{1,5,15}$ (Figure 1). This procedure takes advantage of the means by which pituitary derived ACTH reaches the systemic circulation. As ACTH leaves both sides of the anterior lobe of the pituitary, it drains via small hypophyseal veins to the cavernous sinus, then emp- 


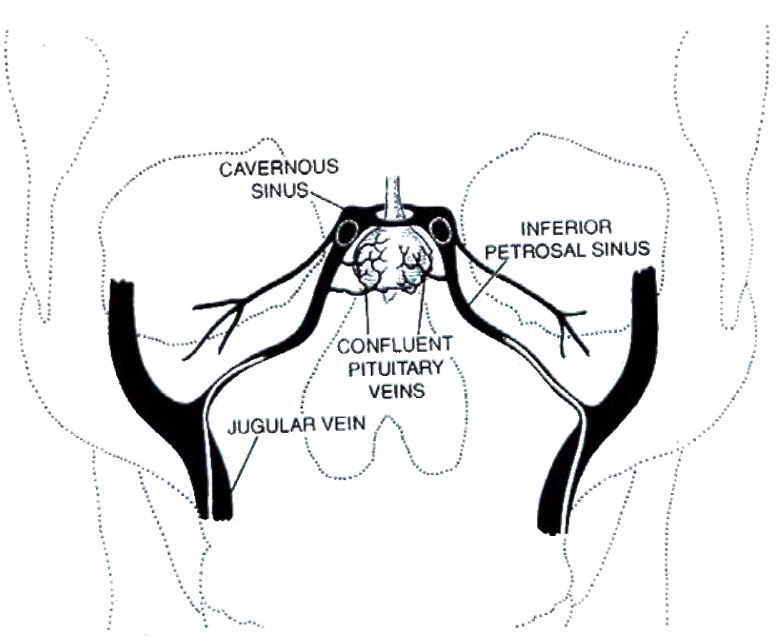

Figure 1. Bilateral simultaneous inferior petrosal sinus sampling (BIPSS). Anatomy of the petrosal sinuses. Reproduced with permission from Oldfield et al.

ties into the inferior petrosal sinus (IPS) and finally to the jugular bulb. Venous sampling from the IPS sinuses and/or the cavernous sinuses is widely practised to confirm a central source of ACTH and to lateralize the site of ACTH hypersecretion. ${ }^{15}$ After successful catheterization and simultaneous sampling of both IPS, a significant ACTH gradient between the pituitary (central) and peripheral values $(\mathrm{C} / \mathrm{P})$, before and particularly after $\mathrm{CRH}$ administration, is indicative of CD.$^{5,15}$ In order to be diagnostic, BIPSS should be performed when peripheral cortisol levels are high enough to suppress the normal pituitary corticotrophs. In order to overcome the possibility that intermittent ACTH secretion may produce false negative results as well as the presence of low basal ACTH ratios from pituitary ACTH-secreting tumours, both human and ovine CRH administra-

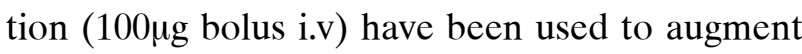
the ACTH response and obtain higher $\mathrm{C} / \mathrm{P} \mathrm{ACTH}$ ratios. ${ }^{5,75}$ Initial reports have suggested that a post$\mathrm{CRH}$ administration $\mathrm{C} / \mathrm{P}$ ACTH ratio of greater than 3 has a $100 \%$ sensitivity and specificity in distinguishing CD from oECS. ${ }^{75}$ This was later confirmed by other studies in which a peak stimulated $\mathrm{C} / \mathrm{P}$ ratio between 2-3, occurring within the first 10 minutes following CRH administration, was shown to be indicative of CD. ${ }^{24,75-82}$ Subsequently, the initially validated criterion of $\mathrm{C} / \mathrm{P}$ ratio required revision downwards to 2 in order to maintain $100 \%$ sensitivity. ${ }^{75} \mathrm{~A}$ recent review of all major published series analyzing the results of BIPSS revealed an overall sensitivity of $96 \%$ and specificity of $100 \%$ when applying the criteria of a basal and CRH stimulated ratio of greater than 2 and 3, respectively, in distinguishing $\mathrm{CD}$ from the oECS. ${ }^{1}$ In a series of 128 patients with ACTH-dependent CS who underwent BIPSS published by St Bartholomew's Hospital, a C/P ACTH ratio greater than 2, obtained 5 minutes after $\mathrm{CRH}$ administration, exhibited a sensitivity of $97 \%$ and a specificity of $100 \%$ in diagnosing $\mathrm{CD}$; two patients with active $\mathrm{CS}$ and histologically proven $\mathrm{CD}$ had a false negative result. ${ }^{11}$ False positive results are extremely rare and may result from either cyclical CS or treatment with cortisol-lowering agents, which, by effectively lowering serum cortisol levels, may desuppress the normal corticotrophs, which might then respond to CRH. ${ }^{1,83}$ BIPSS is technically challenging and must be performed by a radiologist experienced in invasive techniques and even then occasionally either one or both IPS may not be adequately catheterized; even in such cases, a C/P ACTH ratio of greater than 2 obtained between the high internal jugular (HIJ) to peripheral veins can be associated with $100 \%$ specificity in diagnosing $\mathrm{CD} .{ }^{5}$ Similarly to applying peripherally the combination of CRH and DDAVP to improve the diagnostic accuracy, both compounds have been used during BIPSS to augment the ACTH response further and avoid false negative results; however, a false positive response during this procedure has been described. ${ }^{5}$ In order to improve diagnostic accuracy and obviate the need for $\mathrm{CRH}$ administration, direct sampling from the cavernous sinuses has been advocated reaching almost $100 \%$ sensitivity and specificity; ${ }^{84}$ however, this has not been confirmed by a recent prospective study, which found a false negative rate of $20 \%$ by applying cavernous sinus sampling. ${ }^{85}$ Although BIPSS was used for lateralizing a pituitary adenoma secreting ACTH, its usefulness is limited and has been a matter of controversy. ${ }^{15,86} \mathrm{~A}$ gradient of 1.4 or greater between both sides of pituitary had accurately predicted the tumour location in $78 \%{ }^{1}$ of the cases; however, in the same combined literature review of 313 cases, the diagnostic accuracy of BIPSS was found ranging between $50 \%$ and $100 \%$. ${ }^{1}$ The only limitations in performing BIPSS are technical: the presence of an experienced radiologist is essential and centres performing this study should have 
gained considerable experience ${ }^{5}$. Although BIPSS is well tolerated, very occasional side effects have been reported including brainstem vascular damage and haematomas. ${ }^{87-89}$ Cavernous sinus sampling (CVS) is also a powerful method for differentiating $\mathrm{CD}$ from EAS, although tumour localization by CVS can not accurately predict the adenoma site at surgery and therefore it should not be used to guide surgical resection..$^{90}$

\section{Differentiating CD from pseudo-Cushing's states}

A pseudo-Cushing's state comprises some clinical features of CS together with evidence of hypercortisolism, which however resolves following resolution of the primary state, such as the depressed phase of affective disorders, ${ }^{91}$ alcoholism or withdrawal from ethanol intoxication ${ }^{92,93}$ as well as eating disorders (anorexia and bulimia nervosa) $)^{91}$ (Table 4). The differentiation between mild CS and pseudo-Cushing's state is often difficult, as laboratory investigations characteristic of CS, such as elevated UFC, disruption of the normal diurnal cortisol secretion, and lack of plasma cortisol suppression to the DST, may be encountered in both conditions. Definitive biochemical confirmation may be difficult and require repeated testing, although the history may be suggestive and clinical and physical examination may indicate the correct diagnosis of either CS or pseudo-Cushing's state. The hypercortisolism associated with these states is probably centrally mediated through increased secretion of CRH and activation of the HPA-axis, in contrast to the great majority of patients with CS who have suppressed hypothalamic CRH secretion. ${ }^{53}$

A direct comparison of commonly used diagnostic tests between patients with CS and pseudoCushing's states showed that a post LDDST serum

Table 4. Pseudo-Cushing's and 'Cushingoid' like states

Pseudo-Cushing's states

Alcoholic pseudo-Cushing's syndrome

Depression

Eating disorders

Cushingoid-like states

Obesity cortisol value of $38 \mathrm{nmol} / 1$ or more was associated with a sensitivity and a specificity of $90 \%$ and $100 \%$, respectively, for diagnosing $\mathrm{CS} .{ }^{1}$ Patients with $\mathrm{CD}$ also demonstrated a more pronounced ACTH and/or cortisol response to $\mathrm{CRH}$ than patients with pseudoCushing's states. ${ }^{91-93}$ Administration of $\mathrm{CRH}$ in depressed patients is associated with blunted ACTH and cortisol responses, although there is considerable overlap with $\mathrm{CD}$; similarly, administration of DDAVP was associated with a high specificity but relatively low sensitivity. ${ }^{55,91}$ Depressed patients usually demonstrate adequate cortisol response to insulin induced hypoglycaemia (blood glucose levels less than $40 \mathrm{mg} / \mathrm{dl}, 2.2 \mathrm{mmol} / \mathrm{l}$ ), which is also absent in approximately $10 \%$ of patients with CS. ${ }^{34,35}$ In an effort to further improve the diagnostic accuracy, CRH administration following a formal 48 hour LDDST has been used; a post $15 \mathrm{~min}$ CRH administration serum cortisol value greater than $38 \mathrm{nmol} / \mathrm{l}(1.4 \mu \mathrm{g} / \mathrm{dl})$ was found in all patients with CS but none with a pseudo-Cushing's state, thus providing a sensitivity and a specificity of $100 \% .^{44}$ Serum cortisol response following the administration of the opiate antagonists loperamide and naloxone has also been used, but this test has not adequately been validated. ${ }^{13}$ In distinguishing alcohol induced pseudo-Cushing's from $\mathrm{CS}$, the clinical history and blood alcohol level, when detectable, may be of great value. ${ }^{1,13}$ Measurement of serum midnight cortisol may be another means of differentiating pseudo-Cushing's states from CS; however, the diagnostic accuracy of this investigation requires hospital admission and has not been tested in a large number of patients with documented pseudo-Cushing's states. ${ }^{1,38}$ More recently it has been suggested that measurement of salivary midnight cortisol may be as accurate as serum midnight cortisol in distinguishing CS from severe obesity and can be used as an alternative tool. ${ }^{39} \mathrm{~A}$ rare condition that can potentially cause further diagnostic confusion is generalized glucocorticoid resistance state, due to mutations in the ligand binding domain of the glucocorticoid receptor. ${ }^{94-96}$ Such patients have high ACTH and cortisol levels and resistance to dexamethasone suppression, since there is diminished feedback by glucocorticoids; however, they exhibit preservation of the normal circadian rhythm of cortisol secretion although set at a higher level. ${ }^{1}$ 


\section{RADIOLOGICAL DIAGNOSIS OF CUSHING'S SYNDROME}

The vast majority of endogenous $\mathrm{CS}$ is secondary to a pituitary ACTH secreting tumour. Therefore, imaging of the pituitary is essential. Magnetic resonance imaging (MRI) of the pituitary with gadolinium enhancement currently exhibits a sensitivity of approximately $60-70 \%$ in identifying a pituitary microadenoma and should be the imaging modality of choice. ${ }^{20,97-101}$ Approximately 5\% of pituitary microadenomas can take up gadolinium, becoming iso-intense with the normal pituitary in the post-contrast scans; for this reason pre-contrast scans should always be performed, where the tumour is shown as a lesion with lower intensity than the normal pituitary. ${ }^{102}$ A recent study showed that when postcontrast spoiled gradient-recalled acquisition MRI is used in the steady-state (SPGR), it is superior to spin echo (SE) MRI and should be used in addition to conventional SE-MRI. ${ }^{103}$ It should be remembered that up to $10 \%$ of the population may have co-incidental tumours of the pituitary shown on MRI and therefore their presence should not always be taken as indicative of significant pathology. ${ }^{1}$ However, the larger the size of the adenoma the higher is the possibility of being significant. ${ }^{104}$ Pituitary macroadenomas are rare and easily identifiable on MRI. These tumours have significantly higher ACTH and cortisol levels and relative resistance to dexamethasone, a proportionally smaller ACTH response to $\mathrm{CRH}$, and a higher ACTH to cortisol ratio compared to microadenoma. ${ }^{105}$ Some authors have suggested that when the biochemistry is suggestive of $\mathrm{CD}$ and a tumour is identified on MRI, there is a 75-98\% chance that this may correlate with the findings on surgical exploration, a figure approximately the same as with BIPSS. ${ }^{78}$ However, others have demonstrated a correlation of only $52 \%$, suggesting that many pituitary microadenomas are not visualized on MRI and further studies, such as BIPSS, are necessary. ${ }^{98}$

Computerized tomography (CT) of the adrenal glands in patients with ACTH-dependent hypercortisolism reveals bilaterally hyperplastic adrenal glands, with and without nodules; in a proportion of patients with proven $\mathrm{CD}$, the adrenal glands may have a normal appearance. ${ }^{15}$ When laboratory investigations and BIPSS are indicative of oECS, screening for the most common causes of oECS, particularly a CT scan of the chest and mediastinum should be performed using fine overlying cuts to exclude bronchial carcinoid tumours. ${ }^{1,27}$ In order to exclude more rare causes of oECS, such as pancreatic islet cell tumours, intestinal carcinoids tumours, and pheochromocytomas, CT of the abdomen may also be necessary. ${ }^{1}$ If the clinical suspicion is high and conventional imaging has failed to localize an ACTH secreting tumour, imaging with ${ }^{111}$ In-DTPA-octreotide, a radiolabelled somatostatin analogue, can identify bronchial carcinoids of a size greater than $5 \mathrm{~mm}$ with a sensitivity of approximately $70 \%$. The sensitivity of this procedure is higher for gastrointestinal carcinoid tumours. ${ }^{106}$ With prolonged follow-up, initially negative. ${ }^{111}$ In-DTPA-octreotide scans may reveal previously occult bronchial carcinoid tumours, while conventional radiology remains negative, thus facilitating the diagnosis of oECS ${ }^{107}$. Functional imaging using somatostatin receptor scintigraphy has recently provided mixed results for localization of ectopic ACTH secreting tumours ${ }^{15}$. The potential of florine-18-fluorodeoxyglucose PET $\left(\left[{ }^{18} \mathrm{~F}\right]-F D G-P E T\right)$ has recently been applied in a small series of 17 patients and conferred no additional benefit for the detection of ectopic ACTH-secreting tumours beyond existing modalities. ${ }^{108}$

When CS is due to an autonomously functioning adrenal tumour, a unilateral mass, $2 \mathrm{~cm}$ or larger in diameter, is usually seen on adrenal CT. ${ }^{53}$ Since a unilateral cortisol-secreting tumour results in suppression of ACTH secretion, the remaining ipsilateral and contralateral adrenal gland should be atrophic or of normal size. ${ }^{1}$ The presence of hyperplasia suggests an ACTH effect and/or the possible diagnosis of asymmetric macronodular hyperplasia, which may be present in up to $10 \%$ of patients with ACTH-dependent $\mathrm{CS} .{ }^{53}$ In these cases adrenal nodules can be up to $4 \mathrm{~cm}$ in diameter associated with hyperplasia of the non-nodular adrenal tissue. When a single adrenal tumour is present, it is important to make the distinction between an adenoma and a carcinoma, particularly when it is of large size; ${ }^{9}$ although the radiological distinction can reliably be made using certain criteria, further experience is needed. ${ }^{109} \mathrm{In}$ addition to adrenal tumours, some other uncommon causes of autonomous adrenal hypercortisolism may be encountered (Table 1). 


\section{RARE FORMS OF CUSHING'S SYNDROME}

\section{Primary pigmented adrenal nodular dysplasia (PPAND)}

This includes cases of ACTH-independent CS due to small pigmented adrenal nodules. ${ }^{110}$ The clinical manifestations develop earlier than in other causes of CS (usually during the second decade of life) and may be mild or severe. ${ }^{110}$ Biochemical investigations are indicative of ACTH-independent $\mathrm{CS}$ and there is some evidence that the biochemical abnormality may be progressive. ${ }^{111}$ Adrenal CT imaging reveals either uni- or bilateral nodularity with nodule sizes ranging from 'minute' to $3 \mathrm{~cm} .{ }^{111}$ The nodules are not encapsulated (distinguishing them from adenomas) and in the majority of cases there is atrophy of cortical tissue in non-nodular parts of the adrenal (distinguishing them from macronodular adrenal hyperplasia). ${ }^{111}$

\section{The Carney Complex}

This entity is an inherited, autosomal dominant disease of multicentric tumours in many organs, whose molecular pathology has recently been delineated. ${ }^{112}$ The distribution of pathologic manifestations usually involves skin lesions $(80 \%$, pigmented lesions, cutaneous myxomas or both), cardiac myxomas ( $72 \%$, single or multiple), PPAND (45\%), breast lesions $(45 \%)$, pituitary tumours $(10-20 \%$, GH-secreting adenomas), and peripheral nerve lesions. $56 \%$ of male patients have testicular tumours (Sertoli cell, Leydig cell, and adrenal rest tumours). ${ }^{110}$ Approximately $20 \%$ of patients with PPAND may have Carney's complex. ${ }^{110}$ In a high proportion of patients with PPAND a paradoxical, i.e more than 50\%, increase in UFC excretion occurring during the last day of either the LDDST or HDDST can be seen; this delayed paradoxical response may prove a useful diagnostic tool. ${ }^{111,113}$ Linkage analysis at chromosomes 2 p16 and 17q22-q24 revealed putative genetic loci, and recently the responsible gene on 17q22-q24 was identified as type $1 \alpha$ regulatory subunit of cAMP-dependent protein kinase A (PRKARIA); mutations of this gene are observed in the vast majority of Carney complex kindreds and in sporadic cases. ${ }^{111,112,114}$

\section{Macronodular adrenal hyperplasia (MAH)}

Patients with this entity, which is distinct from
PPAND, present with bilateral nodules ranging from $0.5-7 \mathrm{~cm}$ in diameter and variable biochemical and radiological findings; however, the clinical manifestations of MAH do not differ from those encountered in other patients with CS, although the patients tend to be older and have symptoms for a longer period of time. ${ }^{110}$ Biochemically, these patients express variable degrees of adrenal autonomy and can either present as ACTH-dependent or ACTH-independent cases of CS. ${ }^{110}$ Adrenal CT scans show enlarged nodular adrenal glands bilaterally with enlargement of nonnodular areas, although findings can vary widely. The adrenal glands are usually enlarged and lobulated with characteristic interlobular hyperplasia. ${ }^{110,115} \mathrm{Al}$ though its pathogenesis is not precisely known, it is thought to represent a form of CS, initially caused by ACTH hypersecretion but eventually resulting in varying degrees of adrenal autonomy; this is further supported by the finding that approximately $20-40 \%$ of patients with pituitary dependent CS may develop micro- or macronodules in both adrenal glands. ${ }^{110}$

\section{McCune-Albright syndrome}

This syndrome is characterized by polyostotic fibrous dysplasia, café-au-lait pigmentation of the skin, and multiple endocrinopathies, which may include autonomous adrenal hyperplasia and CS. ${ }^{116}$ In affected individuals, clinical manifestations of hypercortisolism occur soon after birth or in early childhood, and adrenal pathology is characterized by nodular hyperplasia and adenoma formation. Its molecular pathology is due to activating mutations of the stimulatory G-protein gene that controls the production of c-AMP in multiple tissues. ${ }^{116}$

\section{Cushing's syndrome secondary to ectopic CRH/AVP production}

Corticotroph hyperplasia and the absence of an identifiable adenoma have been reported in cases of ACTH dependent-CS. ${ }^{68,117}$ In patients undergoing pituitary surgery for $\mathrm{CD}$, the incidence of corticotroph hyperplasia ranges from $0-10 \% .{ }^{117} \mathrm{In}$ such cases the clear demonstration of clinical and biochemical features of CS establishes the potential role of excessive $\mathrm{CRH}$ action in the pathogenesis of hypercortisolism. ${ }^{117}$ A previous report attempted to characterize the cases with ectopic CRH-dependent $\mathrm{CS}$, including tumours such as small cell carcinoma of 
the prostate, pituitary gangliocytoma, medullary thyroid carcinoma (MTC), and mediastinal carcinoid. ${ }^{117}$ The clinical findings of CS indicate that $\mathrm{CRH}$-dependent CS appears to resemble the ACTH-dependent CS with no distinctive discriminating features. ${ }^{68}$

\section{Food induced CS and aberrant hormone receptors in ACTH-independent forms of CS}

Rare sporadic and familial cases of ACTH-independent forms of CS can be attributed to the aberrant expression of hormone receptors other than the ACTH receptor, which result in cAMP accumulation and cortisol release. ${ }^{118,119}$ The aberrant expression of receptors for gastric inhibitory peptide (GIP) has been most frequently associated with ACTH-independent bilateral macronodular adrenal hyperplasia, although a unilateral adenoma has also been reported. ${ }^{118,120-122}$ Since GIP increases post-prandially, the syndrome of food-dependent CS results from inappropriate postprandial cortisol release. In these patients early morning serum cortisol concentrations are low and increase in response to eating. ${ }^{119,121,123}$ Besides GIP receptors, a number of other receptors expressed in the adrenals and causing CS have also been described (Table 1). The presence of aberrant adrenal hormone receptors in cases of adrenal CS has been systemically evaluated with several investigation protocols using either physiologic (upright posture, mixed meals) or pharmacologic (vasopressin, glucagon, gonadotropin-releasing hormone) tests in order to examine the potential modification of cortisol levels. ${ }^{112}$

\section{Other rarely encountered forms of CS}

Although Ghrelin and synthetic GH secretagogues (GHS) have a stimulatory effect on ACTH and cortisol secretion, apart from the well-known GH-releasing activity, ${ }^{124}$ the relationship between hypercortisolism and GHS-R expression has not yet been clearly defined. ${ }^{125}$ Recently, Ghrelin and Ghrelin receptor expression has been described in neuroendocrine tumours, ${ }^{126}$ and specific GHS receptors have been demonstrated in ectopic ACTHsecreting tumours. ${ }^{127}$ Simultaneous expression of ghrelin and GHS-R has also been described in a case of cyclical CS due to an ectopic ACTH secreting lung carcinoid. ${ }^{128}$

\section{SUBCLINICAL CUSHING'S SYNDROME}

Subclinical CS is an issue of recent interest and controversy because of the serendipitous discovery of adrenal incidentalomas during routine use of sophisticated radiologic techniques. ${ }^{9}$ The prevalence of subclinical CS incidentalomas ranges from 5\% to $20 \%$. The discrepancy must be attributed to the different endocrine investigational protocols and criteria used to define hypercortisolism. ${ }^{129-135}$ The definition of subclinical CS relies on the presence of some biochemical features of CS in patients harbouring a serendipitously discovered adrenal mass. Several different alterations in the endocrine tests assessing the function of the HPA-axis, such as loss of cortisol circadian rhythm, increased UFC levels, suppression of ACTH secretion, abnormal CRH stimulation, and dexamethasone suppression tests, can be found in patients with subclinical CS. ${ }^{9}$ In order to circumvent the problem of false positive biochemical tests, it has been suggested that two concomitant alterations should be demonstrated to diagnose subclinical CS. ${ }^{9}$ Even with this approach, it remains difficult to define the entity of cortisol excess truly relevant for the diagnosis of subclinical CS. ${ }^{9}$ Although emerging evidence suggests that subclinical CS may contribute to the development of insulin resistance, the tempting speculation of a very mild variant of endogenous glucocorticoid excess syndrome sharing similar target organ damages and complications with the full-blown disease remains to be proved ${ }^{9}$ and additional research and long term follow-up are needed to guide clinical practice. ${ }^{129}$

\section{CONCLUSIONS}

Cushing's syndrome is a relatively rare disorder which is being recognized more frequently albeit in its more subtle forms. Since CS is associated with high morbidity and mortality, it is crucial to reach an early and accurate diagnosis. Clinical suspicion is of utmost importance as it initiates further investigations for signs such as thinning of the skin, easy bruising, and proximal myopathy which are of high diagnostic significance (Figure 2). Twenty-four hour UFC and the $1 \mathrm{mg}$ overnight DST are used as a screening test as they can also identify some subclini- 


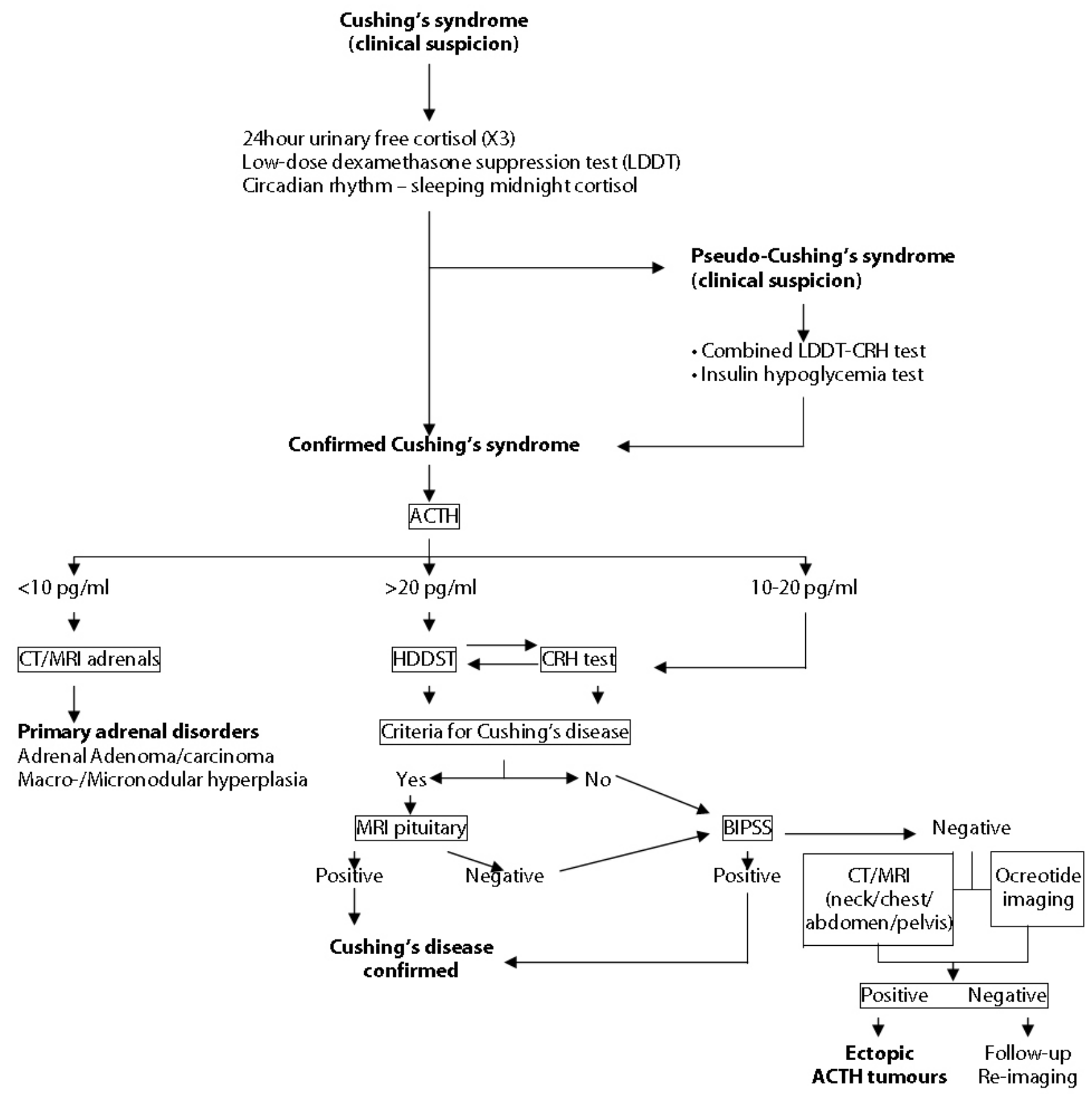

Figure 2. Cushing's syndrome. Diagnostic algorithm.

cal forms of CS; however, both tests are of relatively low specificity for establishing the diagnosis of CS. A 48 hour LDDST can be used as an outpatient screening test and provide the biochemical confirmation of CS. A sleeping midnight serum cortisol measurement is the most specific means of confirming the presence of CS but requires hospital admission. In the event of equivocal results and subtle hypercortisolism, the
LDDST-CRH test may be useful. Following confirmation of CS, measurement of plasma ACTH should be performed; if ACTH is clearly detectable, the investigations should be directed towards a pituitary secreting ACTH tumour, which is by far the most common cause of ACTH-dependent CS. Further diagnostic tests to support the pituitary origin of ACTH secretion are the HDDST and/or the CRH 
stimulation test either alone or in combination with DDAVP; however, recently the diagnostic utility of the HDDST has been questioned. The presence of a microadenoma on pituitary MRI further supports the diagnosis of $\mathrm{CD}$, but the reliable confirmation of a central source of ACTH hyperproduction requires BIPSS. When the biochemical testing and the results of BIPPS are suggestive of a non pituitary source of ACTH secretion, imaging of the thorax and/or the abdomen are necessary to reveal such a source. When imaging studies fail to demonstrate a lesion, radionuclear imaging with ${ }^{111}$ In-pentetreotide can be helpful in selected cases, whereas the role of PET scan is still evolving. In cases where diagnostic problem remains or there is possibility of cyclical CS, thoughtful waiting and reinvestigation at regular intervals may be necessary to reach the correct diagnosis.

Adrenal imaging is the investigation of choice in cases of ACTH-independent CS as it can sufficiently characterize autonomously functioning adenomas and may also help identify those lesions more likely to be carcinomas. With the passage of time more experience is being accumulated in characterizing rare forms of ACTH-independent CS, which should always be considered when bilateral micro- or macronodular adrenal pathology is seen on imaging. Differentiating CS from pseudo-Cushing's states may occasionally be extremely difficult as these entities have common clinical and biochemical features. Measurement of serum midnight cortisol and the combined LDDST-CRH test may prove valuable tools in making such a distinction. Recently, measurement of salivary cortisol has been suggested as being an easily performed method that may supplant serum cortisol measurement, but further validation is required before this test can be incorporated into clinical practices.

\section{REFERENCES}

1.Newell-Price J, Trainer P, Besser M, Grossman A, 1998 The Diagnosis and Differential Diagnosis of Cushing's Syndrome and Pseudo-Cushing's States. Endocr Rev 19: 647-672.

2. Newell-Price J, Morris DG, Drake WM, et al, 2002 Optimal response criteria for the human $\mathrm{CRH}$ test in the differential diagnosis of ACTH-dependent Cushing's syndrome. J Clin Endocrinol Metab 87: 1640-1645.

3. Morris DG, Grossman AB, 2003 Dynamic tests in the diagnosis and differential diagnosis of Cushing's syndrome. J Endocrinol Invest 26: Suppl 7: 64-73.

4. Arnaldi G, Angeli A, Atkinson AB, et al, 2003 Diagnosis and complications of Cushing's syndrome: a consensus statement. J Clin Endocrinol Metab 88: 5593-5602.

5. Kaltsas GA, Giannulis MG, Newell-Price JD, et al, 1999 A critical analysis of the value of simultaneous inferior petrosal sinus sampling in Cushing's disease and the occult ectopic adrenocorticotropin syndrome. J Clin Endocrinol Metab 84: 487-492.

6. Orth DN, 1995 Cushing's syndrome. N Engl J Med 332: 791-803.

7. Boscaro M, Barzon L, Fallo F, Sonino N, 2001 Cushing's syndrome. Lancet 357: 783-791.

8. Reincke M, 2000 Subclinical Cushing's syndrome. Endocrinol Metab Clin North Am 29: 43-56.

9. Terzolo M, Bovio S, Reimondo G, et al, 2005 Subclinical Cushing's syndrome in adrenal incidentalomas. Endocrinol Metab Clin North Am 34: 423-439.

10. Ross NS, 1994 Epidemiology of Cushing's syndrome and subclinical disease. Endocrinol Metab Clin North Am 23: 539-546.

11. Kaltsas GA, Grossman AB, 1998 Malignant pituitary tumours. Pituitary 1:69-81.

12. Kaltsas GA, Nomikos P, Kontogeorgos G, Buchfelder M, Grossman AB, 2005 Clinical review: Diagnosis and management of pituitary carcinomas. J Clin Endocrinol Metab 90: 3089-3099.

13. Newell-Price J, Grossman A, 1999 Diagnosis and mana gement of Cushing's syndrome. Lancet 353: 2087-2088.

14. Ilias I, Torpy DJ, Pacak K, Mullen N, Wesley RA, Nieman LK, 2005 Cushing's Syndrome Due to Ectopic Corticotropin Secretion: Twenty Years' Experience at the National Institutes of Health. J Clin Endocrinol Metab 90: 4955-4962.

15. Lindsay JR, Nieman LK, 2005 Differential Diagnosis and imaging in Cushing's syndrome. Endocrinol Metab Clin North Am 34: 403-421.

16. Stratakis CA, Chrousos GP, 2000 Adrenal cancer. Endocrinol Metab Clin North Am. 29: 15-25.

17. Dacou-Voutetakis C, Chrousos GP, 2003 Editorial Note: Adrenal Incidentalomas or Adrenalomas: The NIH state-of-the-science conference statement. Hormones (Athens) 2: 9-11

18. Linos DA, 2003 Adrenal incidentaloma (adrenaloma). Hormones (Athens) 2: 12-21.

19. Trainer PJ, Grossman A, 1991 The diagnosis and differential diagnosis of Cushing's syndrome. Clin Endocrinol (Oxf) 34: 317-330.

20. Kaye TB, Crapo L, 1990 The Cushing syndrome: an update on diagnostic tests. Ann Intern Med 112: 434-444.

21. Kuhn JM, Proeschel MF, Seurin DJ, Bertagna XY, Luton JP, Girard FL, 1989 Comparative assessment of ACTH and lipotropin plasma levels in the diagnosis and follow-up of patients with Cushing's syndrome: a study of 210 cases. Am J Med 86: 678-684. 
22. Tyrrell JB, Findling JW, Aron DC, Fitzgerald PA, Forsham PH, 1986 An overnight high-dose dexamethasone suppression test for rapid differential diagnosis of Cushing's syndrome. Ann Intern Med 104: 180-186.

23. Aron DC, Raff H, Findling JW, 1997 Effectiveness versus efficacy: the limited value in clinical practice of high dose dexamethasone suppression testing in the differential diagnosis of adrenocorticotropin-dependent Cushing's syndrome. J Clin Endocrinol Metab 82: 1780-1785.

24. Isidori AM, Kaltsas GA, Mohammed S, et al, 2003 Discriminatory value of the low-dose dexamethasone suppression test in establishing the diagnosis and differential diagnosis of Cushing's syndrome. J Clin Endocrinol Metab 88: 5299-5306.

25. Savage MO, Storr HL, Grossman AB, Krassas GE, 2003 Growth and growth hormone secretion in paediatric Cushing's disease. Hormones (Athens) 2: 93-97.

26. Chrousos GP, 2003 Editorial: Growth Management of Children and Adolescents with Cushing's Disease Hormones (Athens) 2: 89-90.

27. Findling JW, Raff H, 2005 Screening and diagnosis of Cushing's syndrome. Endocrinol Metab Clin North Am 34: 385-402.

28. Imura H, Matsukura S, Yamamoto H, Hirata Y, Nakai Y, 1975 Studies on ectopic ACTH-producing tumors. II. Clinical and biochemical features of 30 cases. Cancer 35: 1430-1437.

29. Torring O, Bucht E, Thoren M, Sjoberg HE, 1986 Plasma calcitonin response to a calcium clamp in endogenous Cushing's syndrome. Acta Endocrinol (Copenh) 111: 258-263.

30. Atkinson AB, McCance DR, Kennedy L, Sheridan B, 1992 Cyclical Cushing's syndrome first diagnosed after pituitary surgery: a trap for the unwary. Clin Endocrinol (Oxf) 36: 297-299.

31. Jacobson L, 2005 Hypothalamic-Pituitary-Adrenocortical axis regulation. Endocrinol Metab Clin North Am 34: 271-292.

32. Krieger DT, Allen W, Rizzo F, Krieger HP, 1971 Characterization of the normal temporal pattern of plasma corticosteroid levels. J Clin Endocrinol Metab 32: 266284.

33. Hellman L, Weitzman ED, Roffwarg H, Fukushima DK, Yoshida K, 1970 Cortisol is secreted episodically in Cushing's syndrome. J Clin Endocrinol Metab 30: 686-689.

34. Crapo L, 1979 Cushing's syndrome: a review of diagnostic tests. Metabolism 28: 955-977.

35. Butler PW, Besser GM, 1968 Pituitary-adrenal function in severe depressive illness. Lancet 1: 1234-1236.

36. Ross RJ, Miell JP, Holly JM, et al, 1991 Levels of GH binding activity, IGFBP-1, insulin, blood glucose and cortisol in intensive care patients. Clin Endocrinol (Oxf) 35: 361-367.

37. Newell-Price J, Trainer P, Perry L, Wass J, Grossman A, Besser M, 1995 A single sleeping midnight cortisol has
$100 \%$ sensitivity for the diagnosis of Cushing's syndrome. Clin Endocrinol (Oxf) 43: 545-550.

38. Papanicolaou DA, Mullen N, Kyrou I, Nieman LK, 2002 Nighttime salivary cortisol: a useful test for the diagnosis of Cushing's syndrome. J Clin Endocrinol Metab 87: 4515-4521.

39. Putignano P, Toja P, Dubini A, Pecori Giraldi F, Corsello SM, Cavagnini F, 2003 Midnight salivary cortisol versus urinary free and midnight serum cortisol as screening tests for Cushing's syndrome. J Clin Endocrinol Metab 88: 4153-4157.

40. Mengden T, Hubmann P, Muller J, Greminger P, Vetter W, 1992 Urinary free cortisol vs. 17-hydroxycorticosteroids: a comparative study of their diagnostic value in Cushing's syndrome. Clin Invest 70: 545-548.

41. Trainer PJ, Besser M, 2000 Cushing's disease. Lancet 355: 68.

42. Carroll BJ, Curtis GC, Davies BM, Mendels J, Sugerman AA, 1976 Urinary free cortisol excretion in depression. Psychol Med 6: 43-50.

43. Cizza G, Nieman LK, Doppman JL, et al, 1996 Factitious Cushing syndrome. J Clin Endocrinol Metab 81: 3573-3577.

44. Yanovski JA, Cutler Jr GB, Chrousos GP, Nieman LK, 1993 Corticotropin-releasing hormone stimulation following low-dose dexamethasone administration. A new test to distinguish Cushing's syndrome from pseudo-Cushing's states. JAMA 269: 2232-2238.

45. Blethen SL, Chasalow FI, 1989 Overnight dexamethasone suppression test: normal responses and the diagnosis of Cushing's syndrome. Steroids 54: 185-193.

46. Wood PJ, Barth JH, Freedman DB, Perry L, Sheridan B, 1997 Evidence for the low dose dexamethasone suppression test to screen for Cushing's syndrome-recommendations for a protocol for biochemistry laboratories. Ann Clin Biochem 34: 222-229.

47. Cronin C, Igoe D, Duffy MJ, Cunningham SK, McKenna TJ, 1990 The overnight dexamethasone test is a worthwhile screening procedure. Clin Endocrinol (Oxf) 33: 27-33.

48. Kennedy L, Atkinson AB, Johnston H, Sheridan B, Hadden DR, 1984 Serum cortisol concentrations during low dose dexamethasone suppression test to screen for Cushing's syndrome. Br Med J 289: 1188-1191.

49. Arlt W, Stewart PM, 2005 Adrenal corticosteroid biosynthesis, metabolism, and action. Endocrinol Metab Clin North Am 34: 293-313.

50. Sonino N, Bonnini S, Fallo F, Boscaro M, Fava GA, 2006 Personality characteristics and quality of life in patients treated for Cushing's syndrome. Clin Endocrinol (Oxf) 64: 314-318.

51. Mosnier-Pudar H, Thomopoulos P, Bertagna X, Fournier C, Guiban D, Luton JP, 1995 Long-distance and long-term follow-up of a patient with intermittent Cushing's disease by salivary cortisol measurements. Eur J Endocrinol 133: 313-316.

52. Howlett TA, Drury PL, Perry L, Doniach I, Rees LH, 
Besser GM, 1986 Diagnosis and management of ACTHdependent Cushing's syndrome: comparison of the features in ectopic and pituitary ACTH production. Clin Endocrinol (Oxf) 24: 699-713.

53. Findling JW, Doppman JL, 1994 Biochemical and radiologic diagnosis of Cushing's syndrome. Endocrinol Metab Clin North Am 23: 511-537.

54. Tsigos C, Chrousos GP, 1996 Differential diagnosis and management of Cushing's syndrome. Annu Rev Med 47: 443-461.

55. Grossman AB, Howlett TA, Perry L, et al, 1988 CRF in the differential diagnosis of Cushing's syndrome: a comparison with the dexamethasone suppression test. Clin Endocrinol (Oxf) 29: 167-178.

56. Dichek HL, Nieman LK, Oldfield EH, Pass HI, Malley JD, Cutler Jr GB, 1994 A comparison of the standard high dose dexamethasone suppression test and the overnight 8-mg dexamethasone suppression test for the differential diagnosis of adrenocorticotropin-dependent Cushing's syndrome. J Clin Endocrinol Metab 78: 418-422.

57. Flack MR, Oldfield EH, Cutler Jr GB, et al, 1992 Urine free cortisol in the high-dose dexamethasone suppression test for the differential diagnosis of the Cushing syndrome. Ann Intern Med 116: 211-217.

58. Hermus AR, Pieters GF, Pesman GJ, Smals AG, Benraad TJ, Kloppenborg PW, 1986 The corticotropin-releasinghormone test vs. the high-dose dexamethasone test in the differential diagnosis of Cushing's syndrome. Lancet 2: 540-544.

59. Howlett TA, Grossman A, Rees LH, Besser GM, 1986 Differential diagnosis of Cushing's syndrome. Lancet 11: 871.

60. Raff H, Findling JW, 2003 A physiologic approach to diagnosis of the Cushing syndrome. Ann Intern Med 138: 980-991.

61. Findling JW, Raff H, Aron DC, 2004 The low-dose dexamethasone suppression test: a re-evaluation in patients with Cushing's syndrome. J Clin Endocrinol Metab 89: 1222-1226.

62. Dias R, Storr HL, Perry LA, Isidori AM, Grossman AB, Savage MO, 2006 The discriminatory value of the low-dose dexamethasone suppression test in the investigation of paediatric Cushing's syndrome. Horm Res 65: 159-162.

63. Hermus AR, Pieters GF, Pesman GJ, Smals AG, Benraad TJ, Kloppenborg PW, 1986 Responsivity of adrenocorticotropin to corticotropin-releasing hormone and lack of suppressibility by dexamethasone are related phenomena in Cushing's disease. J Clin Endocrinol Metab 62: 634639.

64. Malchoff CD, Orth DN, Abboud C, Carney JA, Pairolero PC, Carey RM, 1988 Ectopic ACTH syndrome caused by a bronchial carcinoid tumor responsive to dexamethasone,metyrapone, and corticotropin-releasing factor. Am J Med 84: 760-764.

65. Tabarin A, San Galli F, Dezou S, et al, 1990 The corticotropin-releasing factor test in the differential diagnosis of
Cushing's syndrome: a comparison with the lysine-vasopressin test. Acta Endocrinol (Copenh) 123: 331-338.

66. Newell-Price J, Perry L, Medbak S, et al, 1997 A combined test using desmopressin and corticotropin-releasing hormone in the differential diagnosis of Cushing's syndrome. J Clin Endocrinol Metab 82: 176-181.

67. Malerbi DA, Mendonca BB, Liberman B, et al, 1993 The desmopressin stimulation test in the differential diagnosis of Cushing's syndrome. Clin Endocrinol (Oxf) 38: 463-472.

68. Becker M, Aron DC, 1994 Ectopic ACTH syndrome and CRH-mediated Cushing's syndrome Endocrinol Metab Clin North Am 23: 585-606.

69. Yanovski JA, Cutler GB Jr, Chrousos GP, Nieman LK, 1998 The dexamethasone-suppressed corticotropin-releasing hormone stimulation test differentiates mild Cushing's disease from normal physiology. J Clin Endocrinol Metab 83: $348-352$.

70. Kunugi H, Urushibara T, Nanko S, 2004 Combined DEX/CRH test among Japanese patients with major depression. J Psychiatr Res 38: 123-128.

71. Findling JW, Raff H, 2001 Diagnosis and differential diagnosis of Cushing's syndrome. Endocrinol Metab Clin North Am 30: 729-747.

72. Martin NM, Dhillo WS, Banerjee A, et al, 2006 Comparison of the dexamethasone-suppressed corticotropinreleasing hormone test and low-dose dexamethasone suppression test in the diagnosis of Cushing's syndrome. J Clin Endocrinol Metab 91: 2582-2586.

73. Papanicolaou DA, Yanovski JA, Cutler GB Jr, et al, 1998 A single midnight serum cortisol measurement distinguishes Cushing's syndrome from pseudo-Cushing states. J Clin Endocrinol Metab 83: 1163-1167.

74. Castro M, Elias PC, Quidute AR, et al, 1999 Out-patient screening for Cushing's syndrome: the sensitivity of the combination of circadian rhythm and overnight dexamethasone suppression salivary cortisol tests. J Clin Endocrinol Metab 84: 878-882.

75. Oldfield EH, Doppman JL, Nieman LK, et al, 1991 Petrosal sinus sampling with and without corticotropin-releasing hormone for the differential diagnosis of Cushing's syndrome. N Engl J Med 325: 897-905.

76. Findling JW, Kehoe ME, Shaker JL, Raff H, 1991 Routine inferior petrosal sinus sampling in the differential diagnosis of adrenocorticotropin (ACTH)-dependent Cushing's syndrome: early recognition of the occult ectopic ACTH syndrome. J Clin Endocrinol Metab 73: 408-413.

77. Landolt AM, Schubiger O, Maurer R, Girard J, 1994 The value of inferior petrosal sinus sampling in diagnosis and treatment of Cushing's disease. Clin Endocrinol (Oxf) 40: 485-492.

78. de Herder WW, Uitterlinden P, Pieterman H, et al, 1994 Pituitary tumour localization in patients with Cushing's disease by magnetic resonance imaging. Is there a place for petrosal sinus sampling? Clin Endocrinol (Oxf) 40: 
87-92.

79. Lopez J, Barcelo B, Lucas T, et al, 1996 Petrosal sinus sampling for diagnosis of Cushing's disease: evidence of false negative results. Clin Endocrinol (Oxf) 45: 147156.

80. Landolt AM, Valavanis A, Girard J, Eberle AN, 1986 Corticotrophin-releasing factor-test used with bilateral, simultaneous inferior petrosal sinus blood-sampling for the diagnosis of pituitary-dependent Cushing's disease. Clin Endocrinol (Oxf) 25: 687-696.

81. Colao A, Merola B, Tripodi FS, et al, 1993 Simultaneous and bilateral inferior petrosal sinus sampling for the diagnosis of Cushing's syndrome: comparison of multihormonal assay, baseline multiple sampling and ACTH-releasing hormone test. Horm Res 40: 209-216.

82. Colao A, Faggiano A, Pivonello R, et al, 2001 Inferior petrosal sinus sampling in the differential diagnosis of Cushing's syndrome: results of an Italian multicenter study. Eur J Endocrinol 144: 499-507.

83. Yanovski JA, Cutler GB Jr, Doppman JL, et al, 1993 The limited ability of inferior petrosal sinus sampling with corticotropin-releasing hormone to distinguish Cushing's disease from pseudo-Cushing states or normal physiology. J Clin Endocrinol Metab 77: 503-509.

84. Teramoto A, Nemoto S, Takakura K, Sasaki Y, Machida T, 1993 Selective venous sampling directly from cavernous sinus in Cushing's syndrome. J Clin Endocrinol Metab 76: 637-641.

85. Vandorpe RA, Fox AJ, Pelz DM, Lee DH, 1994 Direct sampling of the cavernous sinus in Cushing's disease. Can Assoc Radiol J 45: 234-237.

86. Miller DL, Doppman JL, Nieman LK, et al, 1990 Petrosal sinus sampling: discordant lateralization of ACTH-secreting pituitary microadenomas before and after stimulation with corticotropin-releasing hormone. Radiology 176: 429-431.

87. Seyer H, Honegger J, Schott W, et al, 1994 Raymond's syndrome following petrosal sinus sampling. Acta Neurochir (Wien) 131: 157-159.

88. Sturrock ND, Jeffcoate WJ, 1997 A neurological complication of inferior petrosal sinus sampling during investigation for Cushing's disease: a case report. J Neurol Neurosurg Psychiatry 62: 527-528.

89. Miller DL, 1992 Neurologic complications of petrosal sinus sampling. Radiology 183: 878.

90. Liu C, Lo JC, Dowd CF, et al, 2004 Cavernous and inferior petrosal sinus sampling in the evaluation of ACTH-dependent Cushing's syndrome. Clin Endocrinol (Oxf) 61: 478-486.

91. Gold PW, Loriaux DL, Roy A, et al, 1986 Responses to corticotropin-releasing hormone in the hypercortisolism of depression and Cushing's disease. Pathophysiologic and diagnostic implications. N Engl J Med 314: 1329-1335.

92. Kirkman S, Nelson DH, 1988 Alcohol-induced pseudoCushing's disease: a study of prevalence with review of the literature. Metabolism 37: 390-394.
93. Wand GS, Dobs AS, 1991 Alterations in the hypothalamic-pituitary-adrenal axis in actively drinking alcoholics. J Clin Endocrinol Metab 72: 1290-1295.

94. de Lange P, Koper JW, Huizenga NA, et al, 1997 Differential hormone-dependent transcriptional activation and repression by naturally occurring human glucocorticoid receptor variants. Mol Endocrinol 11: 1156-1164.

95. Bronnegard M, Stierna P, Marcus C, 1996 Glucocorticoid resistant syndromes-molecular basis and clinical presentations. J Neuroendocrinol 8: 405-415.

96. Arai K, Chrousos GP, 1995 Syndromes of glucocorticoid and mineralocorticoid resistance. Steroids 60: 173-179.

97. Dwyer AJ, Frank JA, Doppman JL, et al, 1987 Pituitary adenomas in patients with Cushing disease: initial experience with Gd-DTPA-enhanced MR imaging. Radiology 163: 421-426.

98. Buchfelder M, Nistor R, Fahlbusch R, Huk WJ, 1993 The accuracy of CT and MR evaluation of the sella turcica for detection of adrenocorticotropic hormone-secreting adenomas in Cushing disease. Am J Neuroradiol 14: 1183-1190.

99. Newton DR, Dillon WP, Norman D, Newton TH, Wilson CB, 1989 Gd-DTPA-enhanced MR imaging of pituitary adenomas. Am J Neuroradiol 10: 949-954.

100. Peck WW, Dillon WP, Norman D, Newton TH, Wilson CB, 1989 High-resolution MR imaging of pituitary microadenomas at $1.5 \mathrm{~T}$ : experience with Cushing disease. Am J Roentgenol 152: 145-151.

101. Escourolle H, Abecassis JP, Bertagna X, et al, 1993 Comparison of computerized tomography and magnetic resonance imaging for the examination of the pituitary gland in patients with Cushing's disease. Clin Endocrinol (Oxf) 39: 307-313.

102. Burrow GN, Wortzman G, Rewcastle NB, Holgate RC, Kovacs K, 1981 Microadenomas of the pituitary and abnormal sellar tomograms in an unselected autopsy series. N Engl J Med 304: 156-158.

103. Batista D, Courkoutsakis NA, Oldfield EH, et al, 2005 Detection of Adrenocorticotropin-Secreting Pituitary Adenomas by Magnetic Resonance Imaging in Children and Adolescents with Cushing Disease. J Clin Endocrinol Metab 90: 5134-5140.

104. Hall WA, Luciano MG, Doppman JL, Patronas NJ, Oldfield EH, 1994 Pituitary magnetic resonance imaging in normal human volunteers: occult adenomas in the general population. Ann Intern Med 120: 817-820.

105. Woo YS, Isidori AM, Wat WZ, et al, 2005 Clinical and biochemical characteristics of adrenocorticotropin-secreting macroadenomas. J Clin Endocrinol Metab 90: 4963-4969.

106. Granberg D, Sundin A, Janson ET, Oberg K, Skogseid B, Westlin JE, 2003 Octreoscan in patients with bronchial carcinoid tumours. Clin Endocrinol (Oxf) 59: 793-799.

107. Tsagarakis S, Christoforaki M, Giannopoulou H, et al, 2003 A reappraisal of the utility of somatostatin receptor scintigraphy in patients with ectopic adrenocorticotropin 
Cushing's syndrome. J Clin Endocrinol Metab 88: 47544758.

108. Pacak K, Ilias I, Chen CC, Carrasquillo JA, Whatley M, Nieman LK, 2004 The Role of [18F]Fluorodeoxyglucose Positron Emission Tomography and [111In]-Diethylenetriaminepentaacetate-D-Phe-Pentetreotide Scintigraphy in the Localization of Ectopic Adrenocorticotropin-Secreting Tumors Causing Cushing's Syndrome J Clin Endocrinol Metab 89: 2214-2221.

109. Fig LM, Gross MD, Shapiro B, et al, 1988 Adrenal localization in the adrenocorticotropic hormone-independent Cushing syndrome. Ann Intern Med 109: 547-553.

110. Samuels MH, Loriaux DL, 1994 Cushing's syndrome and the nodular adrenal gland. Endocrinol Metab Clin North Am 23: 555-569.

111. Stratakis CA, Carney JA, Lin JP, et al, 1996 Carney complex, a familial multiple neoplasia and lentiginosis syndrome. Analysis of 11 kindreds and linkage to the short arm of chromosome 2. J Clin Invest 97: 699-705.

112. Lacroix A, Bourdeau I, 2005 Bilateral adrenal Cushing's syndrome: macronodular adrenal hyperplasia and primary pigmented nodular adrenocortical disease. Endocrinol Metab Clin North Am 34: 441-458.

113. Stratakis CA, Sarlis N, Kirschner LS, et al, 1999 Paradoxical response to dexamethasone in the diagnosis of primary pigmented nodular adrenocortical disease. Ann Intern Med 131: 585-591.

114. Kirschner LS, Carney JA, Pack SD, et al, 2000 Mutations of the gene encoding the protein kinase A type I-alpha regulatory subunit in patients with the Carney complex. Nat Genet Sep 26: 89-92.

115. Doppman JL, Miller DL, Dwyer AJ, et al, 1988 Macronodular adrenal hyperplasia in Cushing's disease. Radiology 166: 347-352.

116. Weinstein LS, Shenker A, Gejman PV, Merino MJ, Friedman E, Spiegel AM, 1991 Activating mutations of the stimulatory $\mathrm{G}$ protein in the McCune-Albright syndrome. N Engl J Med 325: 1688-1695.

117. Samuels MH, 1993 Cushing's syndrome associated with corticotroph hyperplasia. The Endocrinologist 3: 242247.

118. Swords FM, Aylwin S, Perry L, et al, 2005 The Aberrant Expression of the Gastric Inhibitory Polypeptide (GIP) Receptor in Adrenal Hyperplasia: Does Chronic Adrenocorticotropin Exposure Stimulate Up-Regulation of GIP Receptors in Cushing's Disease? J Clin Endocrinol Metab 90: 3009-3016.

119. Lacroix A, N'Diaye N, Tremblay J, Hamet P, 2001 Ectopic and abnormal hormone receptors in adrenal Cushing's syndrome. Endocr Rev 22: 75-110.

120. Lacroix A, Bolte E, Tremblay J, et al, 1992 Gastric inhibitory polypeptide-dependent cortisol hypersecretion: a new cause for Cushing's syndrome. N Engl J Med 327: 974-980.

121. Reznik Y, Allali-Zerah V, Chayvialle JA, et al, 1992 Food-dependent Cushing's syndrome mediated by aber- rant adrenal sensitivity to gastric inhibitory polypeptide. N Engl J Med 327: 981-986.

122. N'Diaye N, Tremblay J, Hamet P, De Herder WW, Lacroix A, 1998 Adrenocortical overexpression of gastric inhibitory polypeptide receptor underlies food-dependent Cushing's syndrome. J Clin Endocrinol Metab 83: 27812785.

123. de Herder WW, Hofland LJ, Usdin TB, et al, 1996 Fooddependent Cushing's syndrome resulting from abundant expression of gastric inhibitory polypeptide receptors in adrenal adenoma cells. J Clin Endocrinol Metab 81: 3168-3172.

124. Ghigo E, Arvat E, Ramunni J, et al, 1997 Adrenocorticotropin- and cortisol-releasing effect of hexarelin, a synthetic growth hormone-releasing peptide, in normal subjects and patients with Cushing's syndrome. J Clin Endocrinol Metab 82: 2439-2444.

125. Tamura H, Kamegai J, Sugihara H, Kineman RD, Frohman LA, Wakabayashi I, 2000 Glucocorticoids regulate pituitary growth hormone secretagogue receptor gene expression. J Neuroendocrinol 12: 481-485.

126. Korbonits M, Bustin SA, Kojima M, et al, 2001 The expression of the growth hormone secretagogue receptor ligand ghrelin in normal and abnormal human pituitary and other neuroendocrine tumors. J Clin Endocrinol Metab 86: 881-887.

127. de Keyzer Y, Lenne F, Bertagna X, 1997 Widespread transcription of the growth hormone-releasing peptide receptor gene in neuroendocrine human tumors. Eur J Endocrinol 137: 715-718.

128. Arnaldi G, Mancini T, Kola B, et al, 2003 Cyclical Cushing's Syndrome in a Patient with a Bronchial Neuroendocrine Tumor (Typical Carcinoid) Expressing Ghrelin and Growth Hormone Secretagogue Receptors. J Clin Endocrinol Metab 88: 5834-5840.

129. Grumbach MM, Biller BM, Braunstein GD, et al, 2003 Management of the clinically inapparent adrenal mass (“incidentaloma"). Ann Intern Med 38: 424-429.

130. Reincke M, Nieke J, Krestin GP, Saeger W, Allolio B, Winkelmann W, 1992 Preclinical Cushing's syndrome in adrenal "incidentalomas": comparison with adrenal Cushing's syndrome. J Clin Endocrinol Metab 75: 826832.

131. Ambrosi B, Peverelli S, Passini E, et al, 1995 Abnormalities of endocrine function in patients with clinically "silent" adrenal masses. Eur J Endocrinol 132: 422-428.

132. Terzolo M, Osella G, Ali A, et al, 1998 Subclinical Cushing's syndrome in adrenal incidentaloma. Clin Endocrinol (Oxf) 48: 89-97.

133. Caplan RH, Strutt PJ, Wickus GG, 1994 Subclinical hormone secretion by incidentally discovered adrenal masses. Arch Surg 129: 291-296.

134. Fernandez-Real JM, Ricart-Engel W, Simo R, 1994 Pre-clinical Cushing's syndrome: report of three cases and literature review. Horm Res 41: 230-235.

135. Barzon L, Sonino N, Fallo F, Palu G, Boscaro M, 2003 
Prevalence and natural history of adrenal incidentalomas. Eur J Endocrinol 149: 273-285.

136. Stewart PM 2003 The Adrenal Cortex In: Larsen R, Kronenberg H, Melmed S, Polonsky K (eds) Williams Textbook of Endocrinology, Saunders, USA; pp, 491-551.

137. Ross EJ, Linch DC, 1982 Cushing's syndrome-killing disease: discriminatory value of signs and symptoms aiding early diagnosis. Lancet 2: 646-649.
138. Yanovski JA, Cutler GB Jr, 1994 Glucocorticoid action and the clinical features of Cushing's syndrome. Endocrinol Metab Clin North Am 23: 487-509.

139. Oldfield EH, Ghrousos GP, Schulte HM, et al, 1985 Preoperative lateralization of ACTH-secreting pituitary microadenomas by bilateral and simultaneous inferior petrosal venous sinus sampling. N Engl J Med 312: 100-103. 